\title{
ANALISIS HABITS OF MIND MAHASISWA CALON GURU BIOLOGI
}

\author{
Rikizaputra $^{1)}$, Arlian Firda ${ }^{2)}$ \\ Program Studi Pendidikan Biologi FKIP Universitas Lancang Kuning \\ e-mail ${ }^{l)}$ : rikizaputra@unilak.ac.id \\ e-mail²):arlian_arai@unilak.ac.id
}

\begin{abstract}
ABSTRAK: Dalam menjalankan proses perkuliahan bagi mahasiswa perlu menerapkan berbagai strategi dan upaya agar apa yang ditargetkan dapat tercapai secara maksimal. Strategi dan upaya tersebut harus dilatih agar menjadi sebuah kebiasaan yang positif. Setiap orang memiliki berbagai kebiasaan, salah satunya adalah kebiasaan berpikir. Kebiasaan berpikir yang diharapkan dimiliki oleh setiap orang adalah kebiasaan berpikir cerdas. Kebiasaan berpikir cerdas setiap individu disebut dengan habits of mind (HOM). HOM sangat diperlukan dalam kegiatan pembelajaran agar mahasiswa mampu mengatasi masalah yang dihadapinya. Penelitian yang berjudul "Analisis Habits Of Mind Calon Guru Biologi" ini dilakukan pada mahasiswa Program Studi Pendidikan Biologi FKIP Universitas Lancang Kuning yang berada pada tingkat I, II, III dan IV Tahun Pelajaran 2018/2019 dengan teknik pengambilan sampel secara acak kelas. Penelitian ini bertujuan untuk mengetahui profil HOM. Penelitian dilaksanakan pada bulan maret dengan menggunakan 40 butir angket sebagai isntrumen pengumpul data. Angket tersebut terdiri dari pernyataan positif dan negatif dengan 5 skala likert yang memiliki rentang dari sangat tidak setuju (STS) sampai sangat setuju (SS). Hasil penelitian menunjukkan HOM mahasiswa Pendidikan Biologi FKIP Unilak berada pada kategori sedang yaitu 3,59. Rerata HOM mahasiswa semster 6 lebih tinggi dari pada HOM mahasiswa semester 4 dan 2 dengan masing masing 3,78, 3,51 dan 3,48. Dan 68,25\% mahasiswa memiliki HOM sedang, 30,15\% rendah dan 1,59\% mahasiswa memiliki HOM tinggi.
\end{abstract}

Kata kunci : Habit of Mind, Mahasiswa, Calon Guru Biologi

ABSTRACT: In carrying out the lecture process for students it is necessary to implement various strategies and efforts so that what can be supported by the maximum. These strategies and efforts must be drilled to become a positive habit. Everyone has various habits, one of which is the habit of thinking. The habit of thinking expected by everyone is the habit of intelligent thinking. The habits of intelligent thinking of each individual is called the habit of mind (HOM). HOM is needed in learning activities so that students are able to overcome the problems they face. The study, entitled Analysis of Habits of Mind Candidate Biology Teacher was conducted on students of the Biology Education Departement FKIP Lancang Kuning University who were suitable at levels I, II, III and IV of the 2018/2019 Academic Year with sample techniques that could be used random class. This research is to find 
out the profile of HOM. The study was conducted in March using 40 questionnaires as data collection instruments. This questionnaire consists of positive and negative statements with 5 Likert scales from strongly disagree (STS) to strongly agree (SS). The results showed that the Biology Education Departement FKIP Unilak HOM students were in the medium category, namely 3.59. The average HOM for semester 6 students was higher than that of students in semester 4 and 2 with 3.78, 3.51 and 3.48 , respectively. And $68.25 \%$ of students have medium HOM, 30.15\% low and $1.59 \%$ of students have high HOM.

Keywords: Habits Of Mind, Students, Candidate Biology Teachers

\section{PENDAHULUAN}

Kebiasaan berpikir sangat diperlukan dalam berbagai aktivitas pembelajaran dalam perkuliahan termasuk dalam pembelajaran biologi. Dalam pembelajaran biologi di perguruan tinggi khusus di FKIP Universitas Lancang Kuning, mahasiswa selalu dihadapkan pada berbagai tugas mandiri dan paraktikum. Hal ini tentunya perlu diselesaikan dengan kebiasaan berpikir yang produktif dan efisien agar semua masalah tersebut bisa diselesaikan tepat waktu.

Sains sebagai bagian dari pengetahuan merupakan bagian dari Ilmu Biologi. Sains saat ini hanya dipahami sebagai hasil, meskipun sebenarnya sains juga meliputi pada proses. Pengetahuan, konsep, prinsip dan, fakta, merupakan bagian dari produk sains. Sementara keterampilan dan sikap dan nilai positif mencapai produk merupakan proses dalam sains.

Sikap ilmiah dan berfikir aktif mutlak diperlukan untuk mendapatkan produk sains. Berfikir positif dalam pembelajaran semestinya dibiasakan, sehingga menjadi habits.

Habits of Mind (HOM) yang positif ditandai dengan efisiensi waktu dalam hal yang produktif dan meningkatkan pengetahuan. Kebiasaan positif ini sangat bermanfaat. Melalui ini tujuan belajar akan terarah, teratur, dan tepat guna sehingga pengetahuan bermakna akan dapat diraih (Isfiani, 2016)

Costa dan Kallick (2008) telah mengembangkan HOM dalam 16 indikator diantaranya persisting, managing impulsivity, striving for accuracy, thinking and communicating with clarity and precision, gathering data through all senses, questioning and posing problems, thinking about thinking (metacognition), listening with understanding and empathy, thinking flexibly, creating, imagining, innovating, finding humor, responding with wonderment and awe, applying past knowledge to new situations, taking responsible risk, thinking interdependently, dan rofremaining open to continous learning.

Adapun deskripsi dari masingmasing indikator HOM menurut Costa \& Kallick (2008) adalah:

1. Persisting: Tekun mengerjakan tugas hingga selesai, tidak mudah menyerah 
2. Managing

Impulsity:

Menggunakan waktu untuk hati hati bertindak

3. Listening with understanding and amphaty: Bersedia menerima pandangan orang lain

4. Thinking Flexibility: Mempertimbangkan pilihan dan dapat mengubah pandangan

5. Metacognitive: Berpikir tentang berpikir, menjadi lebih peduli terhadap pikiran, perasaan dan tindakan dan memperhitungkan pengaruhnya pada yang lain

6. Stiving for Accuracy: Menetapkan standar yang tinggi dan selalu mencari cara untuk meningkat

7. Questioning and Problem Posing: Menemukan pemecahan masalah, mencari data dan jawaban

8. Applying past knowledge to new situation: Mengakses pengetahuan terdahulu dan mentransferpengetahuan pada konteks baru

9. Thinking and Communication with Clarity and Precision: Berkomunikasi lisan dan tulisan secara akurat

10. Gathering Data Through all Sense: Memberikan perhatian terhadap sekeliling melalui rasa, sentuhan, bau, pendengaran, dan penglihatan

11. Creating, Magiming and Innovating: Memilih ide-ide dan gagasan baru

12. Responding with Wonderment and Awe: Memiliki rasa ingin tahu dengan misteri alam

13. Taking Responsible Risk:
Mengambil resiko secara
bertanggung jawab

14. Finding Humor: Menikmati ketidaklayakan dan yang tidak diharapkan

15. Thinking Interdependently: Dapat bekerja dan belajar dengan orang lain dalam tim

16. Remining Open to Continuous Learning: Tetap berusaha terus belajar dan menerima bila ada yang tidak diketahuinya.

Marita (2014) mengemukakan bahwa habits of mind adalah keterampilan, sikap, dan nilai yang akan muncul dengan kinerja atau kecerdasan tingkah laku berdasarkan stimulus yang diberikan. Stimulus yangdiberikan akan membimbing siswa menghadapi atau menyelesaikan isu-isu yang ada. Pengembangan dan penerapan enam belas kategori ini diharapkan dapat menuntun mahasiswa menjadi pembelajar yang memiliki tujuan terarah dan bermakna.

\section{METODE PENELITIAN}

Penelitian dilaksanakana pada bulan maret 2019 di Program Studi Pendidikan Biologi FKIP Universitas Lancang Kuning.

Populasi merupakan mahasiswa Prodi Pendidikan Biologi, dengan sampel berasal dari mahasiswa semester 2, semester 4 dan semester 6, yang masing-masing dipilih secara random sampling sebanyak satu kelas.

Pendekatan dalam penelitian ini merupakan deskriptif dengan survey yang tidak memberikan perlakuan, manipulasi pada variabel. Penelitian ini menggambarkan kondisi yang nyata terjadi (Mc Millan dan Schumacher, 2001).

Penelitian menggunakan instrumen angket habits of mind dengan 40 butir pernyataan yang

Bio-Lectura: Jurnal Pendidikan Biologi, Vol 7, No 1, April 2020 


\begin{tabular}{|c|c|c|c|c|c|}
\hline \multirow{2}{*}{$\begin{array}{l}\mathrm{N} \\
\mathrm{o}\end{array}$} & \multirow{2}{*}{$\begin{array}{l}\text { Aspek } \\
\text { HOM }\end{array}$} & \multicolumn{3}{|c|}{ Semester } & \multirow{2}{*}{$\begin{array}{c}\text { Rerat } \\
\mathrm{a}\end{array}$} \\
\hline & & 2 & 4 & 6 & \\
\hline 1 & $P$ & $\begin{array}{c}2,9 \\
3\end{array}$ & $\begin{array}{l}3,4 \\
9\end{array}$ & $\begin{array}{l}4,0 \\
5\end{array}$ & 3,49 \\
\hline 2 & $M I$ & $\begin{array}{l}3,5 \\
2\end{array}$ & $\begin{array}{l}3,2 \\
4\end{array}$ & $\begin{array}{l}3,6 \\
4\end{array}$ & 3,46 \\
\hline 3 & $L U E$ & $\begin{array}{c}3,2 \\
9\end{array}$ & $\begin{array}{l}3,1 \\
2\end{array}$ & $\begin{array}{l}3,8 \\
8\end{array}$ & 3,43 \\
\hline 4 & $T F$ & $\begin{array}{c}3,4 \\
4\end{array}$ & $\begin{array}{l}3,2 \\
9\end{array}$ & $\begin{array}{l}3,4 \\
9\end{array}$ & 3,41 \\
\hline 5 & $M$ & $\begin{array}{c}3,4 \\
9\end{array}$ & $\begin{array}{l}3,3 \\
3\end{array}$ & $\begin{array}{l}3,5 \\
7\end{array}$ & 3,46 \\
\hline 6 & $S F A$ & $\begin{array}{c}3,3 \\
8\end{array}$ & $\begin{array}{l}3,5 \\
7\end{array}$ & $\begin{array}{l}3,6 \\
8\end{array}$ & 3,54 \\
\hline 7 & $Q P B$ & $\begin{array}{c}3,4 \\
9\end{array}$ & $\begin{array}{l}3,3 \\
9\end{array}$ & $\begin{array}{l}3,8 \\
8\end{array}$ & 3,58 \\
\hline 8 & $\begin{array}{l}A N K N \\
S\end{array}$ & $\begin{array}{c}3,5 \\
5\end{array}$ & $\begin{array}{l}3,9 \\
7\end{array}$ & $\begin{array}{l}4,1 \\
2\end{array}$ & 3,87 \\
\hline 9 & $T C P$ & $\begin{array}{c}3,5 \\
2\end{array}$ & $\begin{array}{l}3,5 \\
7\end{array}$ & $\begin{array}{l}3,6 \\
5\end{array}$ & 3,57 \\
\hline 10 & GDTS & $\begin{array}{c}3,7 \\
0\end{array}$ & $\begin{array}{l}3,5 \\
9\end{array}$ & $\begin{array}{l}3,7 \\
6\end{array}$ & 3,68 \\
\hline 11 & CII & $\begin{array}{c}3,9 \\
0 \\
\end{array}$ & \begin{tabular}{|l}
3,6 \\
8 \\
\end{tabular} & $\begin{array}{l}3,7 \\
6 \\
\end{array}$ & 3,78 \\
\hline 12 & $R W A$ & $\begin{array}{c}3,5 \\
0\end{array}$ & $\begin{array}{l}4,0 \\
0\end{array}$ & $\begin{array}{l}3,9 \\
6\end{array}$ & 3,82 \\
\hline 13 & TRS & $\begin{array}{c}3,6 \\
9\end{array}$ & $\begin{array}{l}3,8 \\
2\end{array}$ & $\begin{array}{l}4,1 \\
4\end{array}$ & 3,88 \\
\hline 14 & $F H$ & $\begin{array}{c}3,3 \\
8\end{array}$ & $\begin{array}{l}3,0 \\
9\end{array}$ & $\begin{array}{l}3,3 \\
0\end{array}$ & 3,26 \\
\hline 15 & $T I$ & $\begin{array}{c}3,6 \\
0\end{array}$ & $\begin{array}{l}3,2 \\
9\end{array}$ & $\begin{array}{l}3,5 \\
8\end{array}$ & 3,49 \\
\hline 16 & ROCL & $\begin{array}{c}3,6 \\
4\end{array}$ & $\begin{array}{l}4,0 \\
3\end{array}$ & $\begin{array}{l}4,0 \\
6\end{array}$ & 3,91 \\
\hline & erata & $\begin{array}{c}3,4 \\
8\end{array}$ & $\begin{array}{l}3,5 \\
1\end{array}$ & $\begin{array}{l}3,7 \\
8\end{array}$ & 3,59 \\
\hline
\end{tabular}

dikembangkan berdasarkan dimensi habits of mind menurut Costa dan Kallick (2000). Pernyataan teresebut terdiri dari pernyataan positif dan negatif dengan 5 skala likert yaitu sangat tidak setuju (STS) sampai dengan sangat setuju (SS).

Data dianalisis dengan statistik deskriptif persentase pada setiap variable habits of mind dan sikap ilmiah berdasarkan tingkat kelas dan secara total. Menurut Cavas (2011) kategori angket dikonversikan kedalam 3 kategori yaitu tinggi (rerata 4,41-5,00), sedang (rerata 3,39-4,40), rendah (rerata 1,00-3,38)

\section{HASIL DAN PEMBAHASAN}

Setelah data dianalisis ditemukan profil HOM mahasiswa Prodi Pendidikan Biologi FKIP Unilak. Pada Tabel 1 di bawah ini dapat kita lihat bahwa mahasiswa semester 6 memiliki rerata nilai HOM tertinggi yaitu 3,78 sedangkan HOM terendah dimiliki oleh mahasiswa semester 2 yaitu 3,48.

\section{Tabel 1: Rerata HOM Mahasiswa}

Hasil pada tabel 1 menunjukkan bahwa berbeda semester berbeda pula HOM yang ditemukan. Mahasiswa semster 4 memiliki HOM yang lebih tinggi dari mahasiswa semster 2 dan mahasiswa semster 6 memiliki HOM lebih tinggi dari pada mahasiswa semster 2 dan 4 . Walaupun bila dilihat dari kategorinya semua semster menunjukkan HOM pada kategori yang sama yaitu sedang tetapi secara kunatitas menunjukkan keberagaman rerata. Secara umum HOM menunjukkan rerata 3,59 (kategori sedang).

Dari 16 aspek HOM yang diteliti ditemukan bahwa semua aspek berada pada kategori sedang pada setiap semester. Walaupun berada pada kategori yang sama tetapi menunjukkan angka rerata yang berbedabeda pada setiap aspek HOM. Pada mahasiswa semester 2 aspek Creating, Imagining and Innovating menunjukkan rerata tertinggi yaitu 3,90 sedangkan rerata

Bio-Lectura: Jurnal Pendidikan Biologi, Vol 7, No 1, April 2020 
Remaining open to continuous learning menunjukkan rerata tertinggi yaitu 3,91 dan terendah adalah aspek finding humour yaitu 3,26. paling rendah ada pada aspek persisting yaitu 2,93. Dan pada semester 4, aspek Responding with wonderment and awe

Tabel 2 di bawah ini menunjukkan profil HOM berdasarkan jumlah mahaiswanya pada setiap semester dan kategori. Secara umum mahasiswa Program Studi Pendidikan Biologi FKIP Unilak memiliki HOM pada katagori sedang yaitu 68,25\% mahasiswa dan 30, 15\% lainnya masih rendah serta sangat sedikit sekali mahasiswa yang memiliki HOM tinggi yaitu hanya $1,59 \%$.

Tabel 2 Prosentase Habits Of Mind Mahasiswa

\begin{tabular}{|l|l|c|c|c|c|c|c|}
\hline \multirow{2}{*}{ No } & Mhs/ & \multicolumn{4}{|c|}{ Kategori HOM Mahasiswa } \\
\cline { 3 - 8 } & \multirow{2}{*}{ Smt } & \multicolumn{2}{|c|}{ Rendah } & \multicolumn{3}{|c|}{ Sedang } & \multicolumn{2}{c|}{ Tinggi } \\
\cline { 3 - 8 } & & $\mathrm{n}$ & $\%$ & $\mathrm{~N}$ & $\%$ & $\mathrm{n}$ & $\%$ \\
\hline 1 & 2 & 8 & 12,7 & 13 & 61.90 & 0 & 0 \\
\hline 2 & 4 & 6 & 9,52 & 11 & 64,71 & 0 & 0 \\
\hline 3 & 6 & 5 & 7,93 & 19 & 76,00 & 1 & 4 \\
\hline \multicolumn{2}{|l|}{ Jumlah } & 19 & 30,15 & 43 & 68,25 & 1 & 1,59 \\
\hline
\end{tabular}

$76,00 \%$ mahasiswa semester 6 memiliki HOM pada kategori sedang dan hanya $4 \%$ yang memiliki HOM tinggi. Sedangkan pada mahasiswa semester 2 dan 4 belum ditemukan mahasiswa yang memiliki HOM tinggi. Secara umum mahasiswa semester 2 dan 4 memili HOM pada kategori sedang yaitu $61,90 \%$ semster 2 dan 64 , $71 \%$ semester 4 dan banyak juga ditemukan mahasiswa semester 2,4 dan 6 yang memiliki HOM rendah yaitu masing-masing 12,70\%, 9,52\% dan $7,93 \%$.

Pada kegiatan pembelajaran selalu ada stimulus dan respon dan diantara keduanya ada proses. Paham konstruktuvisme mengajarkan bahwa bagaimana respon yang diberikan seseorang setelah belajar tergantung kemampuan individu tersebut dalam mengolah stimulus dalam proses pembelajaran. HOM merupakan salah satu respon pembelajaran yang ditimbulkan oleh serangkaian stumulus yang diberikan, Stumulus tersebut dapat berupa motivasi, materi dan tugas-tugas pembelajaran. Sesuai teori Classical Conditioning dalam Dahar (1986) yang menyatakan bahwa kegiatan pembelajaran mengajarkan sikap baru pada mahasiswa yang mendorongnya untuk mempelajari sikap-sikap tertentu walaupun terkadang sikap seperti ini tidak disadari oleh mahasiswa.

Kemampuan seseorang untuk bertindak dalam menyelesaikan permasalahan bergantung pada sikap dan kebiasaan mental dalam mengelola stumulus tersebut. Costa dan Kallick (2008) menyatakan bahwa HOM tergantung pada kebiasaan mental. Hal yang sejalan dengan itu juga disampaikan Winkel (1996) yang mengaitkan teori Operant Conditioning dengan sikap pembelajaran, ditemukan bahwa pembelajaran dengan tekun dan akan berdampak pada penguatan terhadap diri pribadi.

Pada penelitian ini sebagaimana pada Tabel 4.1 ditemukan adanya perbedaan rerata HOM antara mahasiswa semster 2, 4 dan 6 yaitu masing masing 3,48, 3,51 dan 3,78. Data ini hanya berbeda sedikit tetapi menunjukkan adanya peningkatan HOM berkorelasi dengan semakin tinggi semester. Hal ini dikarenakan dengan masa kuliah yang semakin lama maka jumlah tugas mereka terima akan semakin banyak mereka berhubungan dengan tugas tugas perkuliahan, seperti 
makalah, tugas tugas observasi lingkungan dan penelitian penelitian penelitian sederhana serta beragam praktikum yang diberikan sehingga ini berpeluang membentuk karakter dan pengalaman pengalaman saintis mahasiswa. Nurmaulita (2014) menemukan bahwa siswa yang belajar melalui pendekatan sains lingkungan teknologi masyarakat (Salingtemas) akan menunjukkan Habit Of Mind (HOM) sangat baik, dapat dilihat dari self regulated thingking, critical thinking dan creative thingking.

HOM dapat terbentuk melalui berbagai jenis penugasan. Costa dan Kallick (2008) menjelaskan bahwa wlapun tugas yang dikerjakan seseorang berbeda- beda, tetapi semua tugas itu dapat mengarahkan terbentuknya HOM jika tugas tersebut dilaksanakan secara konsisten dan berkelanjutan. Kebiasaan belajar dikelas juga memiliki peran dalam pembentukan HOM mahasiswa. Hal yang senada juga ditemukan oleh Sriyati (2011) bahwa HOM akan terbentuk melalui asesmen formatif dalam bentuk strategi penugasan. Mahasiswa yang sudah lama kuliah biasanya beban tugas yang mereka terima juga semakin banyak sehingga inilah yang berkontribusi membentuk HOM mereka.

Kemampuan berpikir cerdas (HOM) sangat perlu dibentuk dan dikembangkan pada berbagai tingkat pendidikan termasuk di perguruan tinggi yang pada dasarnya dihadapkan pada berbagai permasalahan, sehingga dapat menyelesaikan masalah tersebut secara efektif dan efisien (Rustaman, 2008). Hasil penelitian ini menemukan (Tabel 4.1) rerata HOM adalah 3,59. Angka ini menunjukkan bahwa HOM mahasiswa masih berada pada kategori sedang. Ini disebabkan oleh kurang konsistennyanya mahasiswa dalam menyelesaikan tugas dan juga disebabkan oleh pola pikir mereka yang berbeda beda saat menyelesaikan tugas atau permasalahan. Isfiani (2016) menemukan bahwa mindset akan berdampak pada keadaan emosional. Keadaan ini akan muncul dalam kondisi kecemasan pada sisi kognitif. Sehingga secara tidak langsung akan menentukan hasil belajar dan HOM merupakan bagian dari hasil belajar itu. Kondisi HOM mahasiswa pada peneliian ini perlu ditingkatkan lagi dengan berbagai strategi dan pendekatan agar dari kategori sedang bisa mencapai kategori tinggi. Karena HOM merupakan dimensi pembelajaran yang sangat penting. Costa dan Kallick (2008) serta Marzano (1997) menjelaskan bahwa HOM tidak hanya tentang penguasaan konsep, sikap dan keterampilan saja. HOM merupakan gabungan dari ketiga komponen tersebut yang mengarah pada pembentukan kedewasaan kepribadian dan peningkatan intelektual.

Dari 16 aspek HOM yang diteliti, semuanya menunjukkan rerata dari semua semester pada kategori sedang. Tetapi secara kuantitatif aspek Remaining open to continuous learning menunjukkan rerata paling tinggi diantara 15 aspek lainnya yaitu 3,91.Ini menunjukkan bahwa kebiasaan mahasiswa untuk terus belajar dan kesdataran atas ketidatahuannya masih lebih baik dari aspek yang lain. Kondisi seperti ini tentunya harus mendapatkan perhatian dan bimbiingan dari lingkungan agar kecerdasan ini terus berkembang.

Lingkungan memiliki peran penting dalam pembentukan sikap dan 
pengembangan kemampuan dalam pembelajaran. Karena sikap berpikir cerdas perlu dikembangkan dalam proses pembelajaran yang dilakukan secara berkesinambungan. Dosen memiliki peran untuk membentuk sikap mahasiswa. Dosen harus mampu mengondisikan pembelajaran agar terarah apada perhatian yang positif.

Rerata aspek HOM terendah dari 16 aspek ayang ada adalah finding humour yaitu 3,26. Walapun terendah tetapi masih dalam kategori sedang. Walaupun demikian setidanya data ini menunjukkan bahwa kegiatan pembelajaran yang dirasakan mahasiswa belum terlalu menyenangkan, pada hal sesungguhnya menurut Hammond (2013), kondisi yang nyaman dan menyenangkan dalam proses pembelajaran akan meningkatkan kemampuan metakognitif. Dengan kondisi ini akan mendorong terciptanya pembelajaran yang bermakna. Dengan hal ini mahasiswa akan mampu mengaitkan berbagai materi dan tugas dalam pembelajarannya.

Hasil penelitian pada Tabel 4.2 menunjukkan bahwa sebagian besar mahasiswa pada setiap semester miliki HOM sedang. Dan secara umum $68,25 \%$ mahasiswa memiliki HOM sedang. Artinya masih banyak mahasiswa yang miliki HOM rendah. Ini mempertegas bahwa perlunya pembelajaran yang mampu mengarahkan terbentuknya HOM mahasiswa. Pembelajaran yang mampu melatih mental dan daya konsentrasi dan menghindari prilaku prilaku menimbulkan kecemasan pada mahasiswa sehingga bermuara pada terbentuknta HOM. Dosen semestinya melakukan asesmen yang mampu merangsang penalaran. Penggunaan strategi pembelajaran yang tepat juga akan mempengaruhi dan membentuk kebiasaan berpikir yang efisien dan efektif dalam pembelajaran.

Berdasarkan penelitian Cerbin (2011) diketahui bahwa kecemasan berpengaruh terhadap proses akademik, persiapan ujian, dan keyakinan terhadap keberhasilan. Ini menunjukkan bahwa kecemasan kognitif, kebiasaan belajar, HOM danhasil belajar merupakan komponen yang saling mempengaruhi.

\section{KESIMPULAN}

Berdasarkan analisis data yang dilakukan dapat disimpulkan bahwa HOM mahasiswa Pendidikan Biologi FKIP Unilak berada pada kategori sedang yaitu 3,59. Rerata HOM mahasiswa semester 6 lebih tinggi tadi pada HOM mahasiswa semester 4 dan 2 dengan masing masing 3,78, 3,51 dan 3,48 . Dan $68,25 \%$ mahasiswa memiliki HOM sedang, 30,15 rendah dan 1,59 mahasiswa memiliki HOM tinggi.

\section{DAFTARPUSTAKA}

Cerbin, B. (2011). Reducing Test Anxiety. UW-La Crosse Center for Anvancing Teaching \& Learning.

Costa , A.L. \& Kalliks, B. (2000). Describing 16 Habits of Mind. Habits of Mind:A Developmental Series. Alexandria, VA.

Costa, A.L., \& Kallick, B. (2008). Learning and Leading with Habits of Mind 16 Essential Characteristics for Students. Washington DC: Association for Supervision and Curriculum Development

Dahar, R. W. (1988). Teori-Teori Belajar. Bandung: Erlangga. 
Isfiani, I.R. (2016). Profil Tingkatan Habits of Mind dan Kecemasan Kognitif Dalam Mata Pelajaran Biologi Pada Siswa SMA. Biodidaktika, Volume 11 No 2.

Marzano, R.J. (1992). A Different Kind of Classroom. Teaching with Dimensions of Learning. Alexandria: $\quad$ ASCD (Association for Supervision and Curriculum Development.

Marzano, Pickering and McTighe. (1993). Assessing Student Outcomes.Performance Assessment Using the Dimension of Learning Model.Alexandria, Virginia; Association for Supervision and Curriculum Development

Marzano, R.J., dkk. (1997). Dimensions of learning trainer's manual. Alexandria, Virginia USA: Midcontinent Regional Educational Laboratory

Mc. Millan, J. H. \& Schumacher, S. (2001). Research in Education. Fifth Edition. New York: Longman
Nurmaulitas (2014). Pembentukan Habits Of Mind Siswa Melalui Pembelajaran Salingtemas Pada Mata Pelajaran Fisika. Jurnal Pendidikan Fisika Vol. 3 No. 1 Juni 2014

Rustaman, Y.N. (2003). Strategi

Belajar Mengajar Biologi. Common Text Book JICA Edisi Revisi. Bandung: Bilogi FPMIPA UPI.

Rustaman, N.Y. (2008). Kebiasaan Berpikir dalam Pembelajaran Sains dan Asesmennya. Retrieved May 15, 2019 from www.upi.ac.id

Sriyati, S. (2011). Peran asesmen formatif dalam membentuk habits of mind mahasiswa biologi. (Disertasi). Sekolah Pascasarjana, Universitas Pendidikan Indonesia, Bandung. Winkel, W.S., (1996). Psikologi pengajaran. Jakarta: PT. Gramedia Widiasarana Indonesia. 